\title{
Estratégias de sustentabilidade do Movimento Slow Food para fortalecer os territórios rurais
}

\author{
Givaldo Bezerra da Hora ${ }^{1}$
}

\begin{abstract}
Resumo
Desenvolver as potencialidades e fortalecer os territórios rurais significa valorizar as especificidades ambientais, políticas, econômicas e culturais que os representam, de modo a torná-las aspectos essenciais na elaboração de projetos públicos ou privados. Assim, para além do aspecto puramente gastronômico, a filosofia "alimentos bons, limpos e justos" do Movimento Slow Food procura unir sustentabilidade e economia na produção alimentar rural. Por sua vez, esses dois últimos pilares vistos como construções sociais, possibilitam a redução da exclusão do pequeno produtor do mercado, criando condições para que esses atores territorializados resolvam as suas dificuldades mercadológicas. Nesse sentido, busca-se realizar neste artigo uma breve reflexão sobre o papel do Movimento Slow Food no fortalecimento dos territórios rurais e, sobretudo, quais são as suas estratégias para alcançar tal finalidade. Para realizar este exercício foram utilizados como embasamento estudos publicados em artigos que abordam o tema, além de publicações e relatórios do próprio Movimento. Destacam-se como principais resultados a valorização do saber-fazer dos produtores, estreitamento da relação entre esses produtores e os consumidores e a regulação das técnicas de produção mediante à conciliação das diretrizes institucionais do Movimento e as práticas de produção enraizadas no território (embeddedness territorial).
\end{abstract}

Palavras-chave: Movimento Social. Sustentabilidade. Valorização Cultural. Enraizamento Territorial.

\begin{abstract}
Develop the potential and strengthen the rural territories means valuing the environmental, political, economic and cultural specificities that represent them, in order to make them essential aspects in the preparation of public or private projects. Thus, in addition to the purely gastronomic aspect, the "good, clean and fair food" philosophy of the Slow Food Movement seeks to unite sustainability and economy in rural food production. In turn, these latter two pillars, seen as social constructions, enable the reduction of the exclusion of the small producer from the market, creating conditions for these territorial actors to solve their marketing difficulties. In these ways, we intend to carry out in this article a brief reflection on the role of the Slow Food Movement in the strengthening of the rural territories and, above all, what are their strategies to achieve this purpose. To perform this exercise were used as basement studies published in articles that approaches the theme, as well as publications and reports from the Movement itself. The most important results are the appreciation of producers' know-how, the closer relationship between producers and consumers, and the regulation of production techniques through the conciliation of the institutional guidelines of the Movement and production practices embedded in the territory (territorial embeddedness).
\end{abstract}

Keywords: Social Movement. Sustainability. Cultural Valorization.Territorial Embeddedness.

\footnotetext{
${ }^{1}$ Doutorando em Administração. Professor do Instituto Federal de Santa Catarina (IFSC). givaldo.hora@ifsc.edu.br
} 


\section{Introdução}

O desenvolvimento econômico sustentável dos territórios rurais é um tema que deu origem a importantes ações nos campos da política e economia. Os ativos territoriais presentes nesses espaços, não tratados com sustentabilidade após a introdução de inovações implementadas na Revolução Verde, passaram a ser considerados, em tempos recentes, recursos estratégicos que contribuem para o fortalecimento dos produtos e serviços enraizados (embedded ${ }^{2}$ ) na cultura local.

Conforme Denardin (2016), o desafio das estratégias voltadas para o desenvolvimento territorial constitui-se em identificar e ativar os recursos locais específicos, maximizando seus valores ao mesmo tempo em que assegura a sustentabilidade. Nesse sentido, o que se denomina de território possui fatores com características únicas, não transferíveis de uma região para outra. Os recursos podem ser materiais, com especificações tangíveis, como jazidas minerais, florestas solos, rios e lagos, etc., ou intangíveis, como o saber fazer de um agricultor, ligado à sua história, à memória social acumulada de um processo de aprendizagem coletiva e cognitiva (aquisição de conhecimento) e à cultura do local, (PECQUEUR, 2005; DENARDIN, 2016).

Esse modelo de desenvolvimento, segundo Pecqueur (2005), refere-se a uma estratégia de adaptação na medida em que esse processo é reativo em relação à disseminação da globalização. Ou seja, visa permitir ao conjunto de atores dos territórios reorganizarem a economia local face ao crescimento das concorrências na escala mundial, que em relação ao meio rural contribuiu diretamente para "industrialização da agricultura". Assim, vista como contraditória à natureza da própria agricultura, que é buscar a diversidade, os sistemas de produção caracterizados pelo uso de tecnologias padronizadas fortemente presentes no agronegócio, não se mostraram apropriados para incorporarem em suas dinâmicas as demandas dos diferentes povos e populações tradicionais existentes no meio rural (DAL SOGLIO, 2016).

2 O termo embeddedness, traduzido como imersão, incrustação, enraizamento ou imbricamento, fortemente utilizado nas teorias da Nova Sociologia Econômica, tem sua origem na obra " $A$ Grande Transformação", publicado em 1944 pelo antropólogo karl Polany. Tempos depois, o termo foi tomado "emprestado" por Granovetter (1985) o retrabalhando numa forma original, se tornando o grande responsável por sua difusão. 
Embora as estratégias de desenvolvimento territorial possibilitem a diversificação e dinamização das economias interioranas com inclusão de agricultores tradicionais, as mesmas não surgem de modo espontâneo. Na maioria das vezes, são necessárias iniciativas que partam de programas do Estado ou de movimentos da sociedade civil. Frente $a$ isso, torna-se uma proposição compreender esses movimentos em integração às políticas públicas para o fortalecimento dos territórios rurais, em especial na criação e execução de projetos voltados para a promoção da agricultura familiar.

Nesse âmbito, observa-se a atuação do movimento social e econômico Slow Food, fundado pelo italiano Carlo Petrini em 1986, tendo como princípio norteador a defesa da agrobiodiversidade e da cultura alimentar, opondo-se à tendência de padronização do alimento no mundo e incentivando a produção de alimentos bons, limpos e justos para os produtores e consumidores (Slow Food Brasil, 2018). Dentre as suas ações, destacam-se a realização de acordos de cooperação para a integração de políticas públicas na promoção, preservação e a valorização dos alimentos típicos nos territórios onde se concentram números significativos de agricultores familiares (OLIVEIRA, 2014).

Assim, considera-se neste artigo, que o Slow Food apresenta uma relação com o desenvolvimento territorial fundamentada em dois aspectos. O primeiro, de natureza moral, baseada em princípios que expressam os valores do movimento, que converge com o aporte teórico referente à ativação de recursos tangíveis e intangíveis dos territórios rurais, a partir de processos sustentáveis construídos socialmente. E, o segundo, de natureza prática, baseada em ações sociais, econômicas e políticas, mediante a busca de parcerias para a elaboração e execução de projetos que visam a preservação dos alimentos ameaçados de extinção, a identidade cultural dos agricultores e reestruturação do comércio em prol de produtos elaborados com métodos artesanais próprios de um determinado local. Nesta perspectiva, este artigo consiste numa reflexão sobre o papel do Movimento Slow Food no fortalecimento dos territórios rurais, destacando as suas principais estratégias para alcançar tal finalidade. 
Além desta introdução, apresenta-se na segunda parte do artigo o marco teórico constituído por um conjunto de conceitos referente ao que se entende por território e o seu processo de desenvolvimento, destacando seus principais elementos estruturantes. Em seguida, são abordadas as escolhas metodológicas que possibilitaram alcançar o objetivo proposto. Na sequência são analisadas e discutidas as ações do Slow Food em prol dos territórios rurais, evidenciando seus resultados em alguns casos específicos. E, por último, as considerações finais.

\section{A Construção Social do Território}

Devido ao variado conjunto de fatores que compõem o território e o modo pelo qual esse é construído e interpretado, o seu conceito não apresenta uma abordagem universal. Ao contrário, a sua plasticidade leva os estudiosos da área a formularem diferentes concepções, perpassando pelos campos da economia, geografia e sociologia, sendo que cada um apresenta suas próprias definições. Todavia, é importante incorporar nessas variações uma reflexão de natureza relacional, visto que a sua relação com o homem se faz mister para a compreensão do seu processo de desenvolvimento.

Para tanto, pode-se partir de uma constatação social aparentemente simplória: "sem dúvida o homem ${ }^{3}$ nasce com o território, e vice-versa, o território nasce com a civilização" (HAESBAERT; LIMONAD, 2007, p. 42). Quando surge no homem a noção de que vive em um espaço/lugar, e que a utilização dos seus recursos naturais pode transformar a sua paisagem e oferecer condições de desenvolver atividades econômica e cultural, tem-se a construção de um território e a constituição de um ator territorial (Haesbaert; Limonad, 2007). Assim, pensar na concepção desse espaço separado ou independente da sua relação com o homem seria uma fragilidade teórico-empírica que, consequentemente, implicaria numa visão reducionista dessa realidade.

Conforme Raffestin (1993) a formação do território é uma ação posterior ao que se tem como espaço natural. Existe uma dependência do fator humano para existir o território, enquanto o espaço é independe desses dois. É preciso uma ação conduzida por

\footnotetext{
${ }^{3}$ A designação "homem” neste artigo refere-se igualmente a mulheres e homens. 
um ator social para, de fato, existir a "territorialização" do espaço, projetando sua transformação e produzindo relações marcadas pelo poder ${ }^{4}$. Esse autor afirma ser o espaço a "prisão original", enquanto o território é a prisão que os indivíduos constroem para si com o propósito de obter posse, pois aquele primeiro é, por natureza, "dado" como um recurso a ser transformado, uma realidade que antecede qualquer prática humana. Já o território é uma derivação do espaço e retrata a configuração das relações de cooperação e conflito ali construídas.

Nesses termos, nota-se o fato de que a natureza do espaço é uma combinação dialética entre a inércia (estado anterior à construção do território) e a dinâmica (estado que compreende as ações humanas para construção territorial). Ou seja, o indivíduo modifica o lugar de sua forma material para um campo de ação social (Santos, 1996). É, portanto, nesse sentido que se estabelece a relação entre o espaço, homem e concepção de território enquanto uma arena transformada pelas redes e suas dinâmicas.

A dinâmica referente às junções e disjunções no espaço se torna um fenômeno cada vez mais complexo na medida em que surgem novas tecnologias, e com esta se expande o capitalismo. Como consequência dessa dinâmica, vem ocorrendo uma maior emersão de sistemas de produção baseados em redes, e com esta mudança os usos e significados do espaço ganharam diferentes perspectivas, (Harvey, 2009). Para este autor, as elites dirigentes desses espaços podem implementar estratégias de controle de recursos, persuadindo para que as qualidades do lugar passem a ser ressaltadas. Consequentemente, esta ação se torna um grande trunfo na competição espacial entre localidades, podendo contribuir para o surgimento de formas corporativas de governo, "assumindo elas mesmas papéis desenvolvimentistas na produção de climas favoráveis aos negócios e outras qualidades especiais" (Harvey, 2009, p. 266). Notadamente, as diversas formas de relação do homem com o espaço incidem na construção e representação de singulares territórios, não sendo suficiente uma definição única para

\footnotetext{
${ }^{4} \mathrm{O}$ que aqui se entende como poder se manifesta por ocasião da relação em construção. É um processo de troca ou de comunicação quando, na relação que se estabelece, os dois pólos fazem face um ao outro ou se confrontam. Assim, as forças que dispõem os dois parceiros criam um campo de poder (Raffestin, 1993; Bourdieu, 1977).
} 
explicar múltiplas realidades. Diante disso, uma série de correntes teóricas se empenham em interpretar os seus possíveis sentidos e as ações dos atores que os constroem.

Ciente de tais premissas, Haesbaert e Limonad (2007, p. 42) enfatizam que a noção de território deve partir do pressuposto de que:

\begin{abstract}
i) primeiro é necessário distinguir território de espaço (geográfico), eles não são sinônimos, apesar muitos autores utilizarem indiscriminadamente os dois termos - o segundo é muito mais amplo que o primeiro; ii) o território é uma construção histórica e, portanto, social, a partir das relações de poder [...], que envolvem, concomitantemente, a sociedade e espaço geográfico [...]; e iii) o território possui tanto uma dimensão mais subjetiva, que se propõe denominar [...] de consciência, apropriação ou mesmo, em alguns casos, identidade territorial, e uma dimensão mais objetiva, que se pode denominar de dominação do espaço, num sentido mais concreto, realizada por instrumentos de ação político-econômica.
\end{abstract}

Segundo Cazella, Bonnal e Maluf (2009, p. 26), “para vários geógrafos, o território é considerado um "conceito-mala" pelo fato de carregar diversos sentidos. Sua integração no campo da Geografia é relativamente recente - décadas de 1970 e 1980". Esses autores destacam que nesse mesmo período os conhecimentos desenvolvidos pelos estudiosos dessa ciência foram disseminados para outras áreas como Sociologia, Antropologia, Economia e Política. Como resultado dessa interdisciplinaridade surgiram novos aportes teóricos e uma variedade de interpretações sobre a concepção território e quais atores o constitui. Deste modo, para fins didático-analíticos, o Quadro 1 apresenta diferentes abordagens a respeito do conceito de territórios: jurídico-política, cultural e econômica. 


\section{Quadro 1 - As Abordagens Conceituais de Território em Três Vertentes Básicas}

\begin{tabular}{|c|c|c|c|c|}
\hline \multirow{2}{*}{$\begin{array}{c}\text { Dimensão } \\
\text { privilegiada }\end{array}$} & \multirow[b]{2}{*}{ Concepções correlatas } & \multirow{2}{*}{$\begin{array}{l}\text { Concepção de } \\
\text { território }\end{array}$} & \multicolumn{2}{|c|}{ Territorialização } \\
\hline & & & $\begin{array}{c}\text { Principais } \\
\text { atores/agentes }\end{array}$ & $\begin{array}{l}\text { Principais } \\
\text { vetores }\end{array}$ \\
\hline $\begin{array}{l}\text { Jurídico-política } \\
\text { (majoritária, } \\
\text { inclusive no } \\
\text { âmbito da } \\
\text { Geografia) }\end{array}$ & $\begin{array}{l}\text { - Estado-nação; } \\
\text { - Fronteiras políticas e } \\
\text { limites político- } \\
\text { administrativos. }\end{array}$ & $\begin{array}{l}\text { Um espaço } \\
\text { delimitado e } \\
\text { controlado } \\
\text { sobre/por meio do } \\
\text { qual se exerce um } \\
\text { determinado poder, } \\
\text { especialmente o de } \\
\text { caráter estatal. }\end{array}$ & $\begin{array}{l}\text { - Estado-nação; } \\
\text { - Diversas } \\
\text { organizações } \\
\text { políticas. }\end{array}$ & $\begin{array}{l}\text { Relações de } \\
\text { dominação } \\
\text { política e } \\
\text { regulação. }\end{array}$ \\
\hline Cultural (ista) & $\begin{array}{l}\text { - Lugar e cotidiano; } \\
\text { - Identidade e alteridade } \\
\text { social; } \\
\text { - Cultura e imaginário } \\
\text { (imaginário: "conjunto de } \\
\text { representações, crenças, } \\
\text { desejos, sentimentos, em } \\
\text { termos dos quais um } \\
\text { indivíduo ou grupo de } \\
\text { indivíduos vê a realidade e } \\
\text { a si mesmo"). }\end{array}$ & $\begin{array}{l}\text { Produto } \\
\text { fundamentalmente } \\
\text { da apropriação do } \\
\text { espaço feita através } \\
\text { do imaginário e/ou } \\
\text { da identidade } \\
\text { social. }\end{array}$ & $\begin{array}{l}\text { - Indivíduos; } \\
\text { - Grupos étnico- } \\
\text { culturais. }\end{array}$ & $\begin{array}{l}\text { Relações de } \\
\text { identificação } \\
\text { cultural. }\end{array}$ \\
\hline $\begin{array}{l}\text { Econômica } \\
\text { (muitas vezes } \\
\text { economicista } \\
\text { minoritária) }\end{array}$ & $\begin{array}{l}\text { - Divisão territorial do } \\
\text { trabalho; } \\
\text { - Classes sociais e relações } \\
\text { de produção. }\end{array}$ & $\begin{array}{l}\text { (des)territorializaçã } \\
\text { o é vista como } \\
\text { produto espacial do } \\
\text { embate entre } \\
\text { classes sociais e da } \\
\text { relação capital- } \\
\text { trabalho. }\end{array}$ & $\begin{array}{l}\text { - Empresas } \\
\text { (capitalistas); } \\
\text { - } \\
\text { Trabalhadores; } \\
\text { - Estados } \\
\text { enquanto } \\
\text { unidades } \\
\text { econômicas. }\end{array}$ & $\begin{array}{l}\text { Relações } \\
\text { sociais de } \\
\text { produção. }\end{array}$ \\
\hline
\end{tabular}

Fonte: Haesbaert e Limonad (2007).

A concepção de território é, portanto, constituída por um conjunto de dimensões objetivas e subjetivas que, permitem analisar as peculiaridades dos recursos locais, a tessitura das relações construídas entre seus atores e suas implicações socioeconômicas e ambientais. Em síntese, a sua compreensão contribui para a elaboração de políticas e projetos de desenvolvimento capazes de atender as necessidades das populações fragilizadas, em especial nos espaços rurais que se encontram ameaçadas pelo processo de globalização.

Essa perspectiva confere aos estudos dos espaços rurais a análise de uma realidade empírica que evidencia a legitimidade das seguintes proposições: as atividades 
realizadas nessas regiões são amplas e intersetoriais, não se resumindo apenas à produção de alimentos para abastecer os mercados; a tessitura das suas relações sociais é constituída por uma variedade de atores, incluindo, por exemplo fornecedores, consumidores e organizações da sociedade civil; a partir das dinâmicas do território é possível demonstrar que o seu processo de desenvolvimento rural não é um resultado exclusivo das atividades agropecuárias, opondo-se, dessa forma, à ideia de crescimento econômico; o território se constitui a partir da interação do homem com a natureza, formando um sistema socioecológico (Abramovay, 2010). Neste sentido, a multidimensionalidade do território propõe novas alternativas para o desenvolvimento rural, estabelecendo uma valorização da diversificação econômica, sustentabilidade dos recursos e cultura locais.

\section{Especificação de Ativos Territoriais e Desenvolvimento Rural}

A noção de desenvolvimento territorial vem ganhando uma importante atenção dos pesquisadores e de outros grupos sociais que estão envolvidos com questões referentes ao desenvolvimento econômico. Segundo Abramovay (2010, p. 27), a discussão relacionada ao desenvolvimento com enfoque no dinamismo territorial "ganha ímpeto a partir do início dos anos 1980, com base na literatura neo-marshalliana que soube identificar nos laços diretos entre atores sociais uma das razões para a formação de sistemas produtivos localizados [...]". Em tempos recentes, diferenciar desenvolvimento territorial de outros conceitos ligados a noção de território é essencial.

Sendo assim, Carrière e Cazella (2006) apontam que é comum a dúvida sobre as possíveis diferenças teórico-metodológicas envolvidas nas noções de desenvolvimento local e desenvolvimento territorial. Esses autores explicam que se numa fase inicial se falava em desenvolvimento local, atualmente é preferível falar em desenvolvimento territorial, já que este "estilo" de desenvolvimento não se reduz à pequena dimensão.

O desenvolvimento territorial, em sua essência, se caracteriza a partir da constituição de uma entidade produtiva enraizada (embedded) num espaço geográfico. Esse estilo de desenvolvimento "designa todo processo de mobilização dos atores que 
leve à elaboração de uma estratégia de adaptação aos limites externos, na base de uma identificação coletiva com uma cultura e um território" (PECQUEUR, 2005, p. 12). É um desenvolvimento que, segundo Pecqueur (2005), abrange uma estratégia de adequação uma vez que é reativo em relação às soluções liberais do quadro macroeconômico. Ou seja, objetiva possibilitar aos atores dos territórios reestruturarem a economia local diante do aumento das concorrências na escala global.

O referido autor evidencia também que o desenvolvimento territorializado tem, como base, o princípio de especificação dos ativos, isto é, a busca pelos recursos singulares ao território que permitem diferenciá-lo e se posicionar em relação à outras localidades, sem submeter-se à lógica de um mercado baseado na concorrência por produtos padronizados, como vem instigando o modelo do comércio globalizado. É, por esta via, um mecanismo de valorização da cultura, do conhecimento enraizado no território e de recursos materiais, ambientais e simbólicos.

Neste texto adota-se como conceito de "recursos" o apresentado por Pecqueur (2005). Conforme este autor, os recursos são os fatores de um território a serem explorados, organizados ou revelados. No entanto, essa condição tende a mudar quando um processo de identificação e valorização desses recursos latentes se concretiza, os tornando o que se denomina de "ativos territoriais". Tanto os "recursos" como os "ativos" territoriais podem ser qualificados, segundo a sua natureza, em genéricos e específicos.

Os "recursos e ativos genéricos" se definem pelo fato que seu valor ou seu potencial não estão condicionados à uma dependência de sua participação em qualquer processo de produção. Os ativos e recursos são assim totalmente transferíveis, seu valor é legitimado pela ação da troca, que por sua vez tem como lugar o mercado. Quanto ao critério de apreciação do valor de troca, tem-se o preço, o qual é determinado por uma oferta e uma demanda de caráter quantitativo. Em resumo, o fator genérico é independente do "gênio do local" onde é produzido (PECQUEUR, 2005).

De forma contrária, os chamados ativos específicos existem como tais. Porém, seu valor é uma variável dependente das condições próprias do seu uso. É estabelecida a compreensão de que enquanto a transferibilidade do ativo genérico é total, a do ativo 
específico gera custo mais ou menos alto e irredutível. Em relação aos recursos específicos, esses só existem no "estado virtual" e, na prática, não podem passar pelo processo de transferência devido à sua intangibilidade. Essa impossibilidade se explica pelo fato desses recursos nascerem de uma interatividade, constituindo a expressão do processo cognitivo iniciado no momento que atores possuidores de distintas habilidades as colocam em comum e, como resultado, permitem a produção de novos conhecimentos (Pecqueur, 2005; (DENARDIN, 2016).

Nessa direção, "as estratégias de especificação de ativos territoriais podem ser consideradas formas de valorização das vantagens sustentáveis dos territórios, na perspectiva de contribuir para a qualificação de seu processo de desenvolvimento" (Dallabrida, 2016, p. 188). A partir desse ponto de vista, faz-se justificada a intensificação dos debates em torno da emergência de integrar essa abordagem no planejamento de novas estratégias de desenvolvimento rural, considerando sobretudo sua contribuição para a redução das contradições, das incertezas e dos riscos de um processo econômico ecologicamente predatório e socialmente excludente (BONNAL; CAZELLA; DELGADO, 2012).

Bonnal, Cazella e Delgado (2012) apontam que esse tipo de enfoque teórico, relacionado ao fortalecimento das áreas rurais, apresenta um importante avanço quando comparado com as concepções do mainstream econômico, nas quais prevalece uma visão eminentemente setorial. Assim, não condicionado aos modelos resultantes das evoluções recentes da economia internacional, responsável pelo direcionamento das políticas públicas para a agricultura desvinculada da realidade intersetorial, a fundamentação do desenvolvimento territorial busca compreender as novas e complexas interconexões existentes entre os diferentes setores da economia, bem como o conjunto de categorias sociais presentes no mundo rural e, também, as suas articulações com os espaços urbanos (BONNAL; CAZELLA; DELGADO, 2012).

É, portanto, mediante essa interconexão que a especificação de recursos se realiza, dando origem aos produtos e serviços de um território. Esta dinâmica permite a construção de novos significados ao que se entende por desenvolvimento rural, ampliando as possibilidades dos seus atores de protagonizarem na elaboração e execução 
de projetos, com a cooperação de diversas outras organizações para além daquelas pertencentes ao Estado.

Conforme Cazella, Bonnal e Maluf (2009), a descentralização políticoadministrativa do Estado é uma condição sem a qual as lideranças de uma localidade rural, encontram muita dificuldade em participar com autonomia na elaboração e execução de programas direcionados para o desenvolvimento territorial. Nessas circunstâncias, considera-se que esse modelo de desenvolvimento "é tributário de um processo de educação e de formação, que procura requalificar o saber-fazer local, lançando mão de novas tecnologias. Isso impõe incluir, nos projetos locais, programas de informação, de formação e de educação" (CAZELLA; BONNAL; MALUF, 2009, p. 40).

Ao eleger o desenvolvimento territorial como arcabouço teórico para tratar da realidade dos espaços rurais, instaura-se um processo de ampliação das categorias analíticas utilizadas para interpretar a diversidade que constitui as suas características. $\mathrm{O}$ espaço-território é, portanto, o resultado da interação de diversos atores nas suas dimensões econômica, sociocultural e ambiental.

\section{Quadro Metodológico}

Delinear uma "trilha" metodológica que possibilite compreender o papel de um Movimento internacional (Slow Food) no fortalecimento dos territórios rurais e destacar as suas principais estratégias, requer a utilização de categorias analíticas ancoradas numa abordagem que aponte para a importância da interdisciplinaridade, tendo em vista a complexidade que constitui as dinâmicas dos territórios no seu processo de construção.

O quadro teórico do desenvolvimento territorial, aqui apresentado como resultado de uma pesquisa exploratória, ofereceu condições para que a atuação do Slow Food nos territórios rurais fosse analisada a partir de uma perspectiva multidimensional, permitindo identificar e interpretar as suas principais estratégias. No Quadro 2 são descritas as dimensões e suas categorias de análise adotadas neste estudo. 
Quadro 2 - Dimensões e Categorias Analíticas

\begin{tabular}{|c|c|c|}
\hline & Dimensão & Categorias de análise \\
\hline \multirow{3}{*}{$\begin{array}{l}\text { (ABRAMOVAY, 2010; } \\
\text { BONNAL; CAZELLA; } \\
\text { DELGADO, 2012; } \\
\text { CAZELLA, BONNAL, } \\
\text { MALUF, 2009; } \\
\text { PECQUEUR, 2005) }\end{array}$} & Socioeconômica & $\begin{array}{l}\text { - Valorização e ampliação de produtos e serviços } \\
\text { derivados dos recursos territoriais; } \\
\text { - } \quad \text { Reestruturação da organização produtiva e à construção } \\
\text { social de mercados; } \\
\text { - } \begin{array}{l}\text { Desenvolvimento e valorização da cooperação visado } \\
\text { aumento do desempenho econômico do território. }\end{array} \\
\end{array}$ \\
\hline & Socioambiental & $\begin{array}{l}\text { - Preservação das paisagens rurais, valorizando-as aos } \\
\text { olhos da sociedade; } \\
\text { - Construção e fortalecimento de sistemas sociais } \\
\text { ecológicos relacionados à utilização de recursos; }\end{array}$ \\
\hline & Sociocultural & $\begin{array}{l}\text { - Ações direcionadas para o protagonismo e integração } \\
\text { dos atores territoriais; } \\
\text { - Estímulos à aproximação do rural ao meio urbano, e } \\
\text { estreitamento dos laços culturais entre produtor e } \\
\text { consumidor; } \\
\text { - Difusão de inovação e conhecimento entre os atores do } \\
\text { território; } \\
\text { - Requalificação do saber-fazer local, valorizando assim a } \\
\text { identidade cultural enraizada no território. }\end{array}$ \\
\hline
\end{tabular}

Fonte: Elaborado pelo autor a partir do quadro teórico apresentado.

A delimitação das três dimensões buscou incluir o aspecto social em todas as atividades dos territórios rurais, haja vista que suas dinâmicas são impulsionadas pela interação dos seus diversos atores. As fontes de evidências relacionadas às ações estratégicas do Slow Food acessadas para a análise/reflexão aqui apresentada foram basicamente relatórios cedidos pelo projeto Alimentos Bons, Limpos e Justos: ampliação e qualificação da participação da agricultura familiar brasileira no Movimento Slow Food (parceria entre Slow Food, Universidade Federal de Santa Catarina/UFSC e Secretaria Especial para Agricultura Familiar e Desenvolvimento Agrário/SEAD, do Governo Federal), além de publicações de cartilhas no site oficial do Slow Food Brasil, teses e artigos desenvolvidos com a finalidade de investigar problemáticas de diversas ordens relacionadas a este movimento.

Por fim, a interpretação dos dados coletados foi realizada aplicando-se o método de análise de conteúdo. Neste percurso analítico foram revisitadas as proposições teóricas do desenvolvimento territorial que fundamentam este estudo, possibilitando a 
comparação entre o que afirmam as concepções científicas relacionadas ao tema em questão e a realidade empírica do fenômeno analisado.

\section{Ações Estratégicas Slow Food e o Desenvolvimento Territorial}

A origem do Slow Food está diretamente relacionada ao que se conhece como fast food. Foi no ano de 1986 que, em ato reativo à instalação de uma franquia do restaurante McDonald's na capital da Itália, mais precisamente na Piazza di Spagna, o jornalista e ativista alimentar Carlo Petrini fundou na cidade de Bra, localizada no interior daquele mesmo país, o movimento Slow Food na qualidade de associação enogastronômica (COSTA, 2015; SLOW FOOD, 2018).

Para que o Movimento ganhasse força e alcançasse seguidores em outros países, Petrini fundamentou a sua militância na defesa do "direito ao prazer, à convivência em torno ao alimento, propondo outras maneiras de fazer agricultura, que respeitassem e tornassem mais digno o trabalho das pessoas que produzem alimentos" (COSTA, 2015, p. 28). Em síntese, o seu objetivo inicial era apoiar e defender a boa comida, o prazer gastronômico e um ritmo de vida mais lento (SLOW FOOD, 2013a; COSTA, 2015). Configurava-se, naquele momento, o início de uma das mais importantes "críticas ativistas" ao modo de vida mercantilizado pelo processo de globalização, no que se refere especificamente à mecanização da produção agrícola e os seus efeitos diretos na dinâmica dos territórios rurais, tais como o desaparecimento da cultura e saberes tradicionais dos camponeses, redução da biodiversidade e qualidade dos alimentos produzidos (PETRINI, 2009). Congruente a este fato ocorreu uma marginalização socioeconômica dos agricultores tradicionais, a poluição das águas e a saturação dos solos devido à grande derrubada de árvores e o uso intenso de insumos químicos.

Portanto, esse contexto de modernização dolorosa (GRAZIANO DA SILVA, 1981), significou uma desconexão entre agricultura e agricultores, os quais passam paulatinamente a ser um mero elo, porém bastante fraco, de uma complexa cadeia de negócios e de trocas dominada pelo agrobusiness. Era, sem dúvidas, a decadência da autonomia do "homem" do campo. Esse fato ajuda a justificar o comportamento de 
insegurança do agricultor frente ao mercado e "pela sua incapacidade de resistir aos apelos com que as indústrias os bombardeiam para que adotem suas "inovações tecnológicas", normalmente a custos crescentes, e que reduzem sistematicamente a chance de lucro na agricultura" (DAL SOGLIO, 2016, p. 15).

Diante desses conflitos, o Movimento Slow Food tem desempenhando um importante papel para resgatar os valores inerentes ao que se entende como qualidade dos alimentos e dos seus mecanismos de produção, pautados no modelo da agricultura tradicional. Assim, um alimento de qualidade deve ser:

\begin{abstract}
a) bom: o sabor e o aroma de um alimento reconhecível por sentidos bem treinados e educados, são o resultado do bom trabalho do produtor e da escolha de matérias-primas e métodos de produção, que não devem alterar a sua naturalidade; b) limpo: o meio ambiente precisa ser respeitado, devendo ser implementadas práticas sustentáveis de cultivo, criação, processamento, marketing e consumo. Cada etapa da cadeia de produção, incluindo-se o consumo, deve preservar os ecossistemas e a biodiversidade, defendendo a saúde do consumidor e do produtor; e c) justo: é importante que haja justiça social, adotando condições de trabalho que respeitem o ser humano e seus direitos, capazes de gerar remunerações adequadas; uma economia global equilibrada; a prática da compaixão e da solidariedade; o respeito pela diversidade cultural e pelas tradições (SLOW FOOD, 2013a, p. 9).
\end{abstract}

Observa-se nos valores construídos pelo movimento um conjunto de princípios que, teoricamente, corresponde à alguns dos aspectos da abordagem construtivista do desenvolvimento territorial rural. Assim, deste ponto do artigo em diante serão analisadas algumas das suas práticas que, por sua vez, evidenciam aproximação empírica com as perspectivas multidimensionais do quadro teórico apresentado na seção anterior.

A princípio, constatou-se o esforço do Slow Food para acessar diferentes localidades e, com isso, identificar os seus recursos e ativos territoriais em perigo de extinção, mas com potencial de fomentar a economia local quando incluídos nos cuidados de um projeto com viés para o desenvolvimento territorial sustentável. Para atingir tal finalidade com êxito, o movimento instituiu uma descentralização no gerenciamento das suas ações, contando com redes de colaboradores distribuídas em diversos países.

Reside, neste fenômeno, portanto, uma política estratégica dos seus líderes fundadores em obter a cooperação de outros atores capazes de fortalecer e multiplicar a 
rede. Do ponto de vista teórico, essa prática pode ser compreendida como a habilidade que determinados atores possuem em obter uma ação coletiva, e isso requer que os participantes dessa ação sejam induzidos a cooperar (FLIGSTEIN, 2014). Não é possível desenvolver projetos relacionados ao desenvolvimento territorial e, tampouco, executálos, sem direcionar esforços para unir atores em estruturas de redes que possam se comunicar e empreender diversas atividades a partir de um processo cooperativo (CAZELLA; BONNAL; MALUF, 2009). Assim, para esses autores, as estruturas de intercâmbio entre diversos atores, vinculados à diferentes realidades sociais e políticas, representam uma importante "via" para motivar a discussão e desenvolvimento de novos projetos de interesse do território.

Essas redes de cooperação do Slow Food são constituídas por associados, pesquisadores vinculados à institutos e universidades, companhias privadas, cozinheiros, produtores, consumidores e órgãos governamentais. É a partir da contribuição de atores como esses que o Slow executa a identificação e catalogação de alimentos que constituem a sociobiodiversidade e as tradições alimentares locais, criando um registro denominado de Arca do Gosto (SLOW FOOD, 2018).

De acordo com o Slow Food Brasil (2018), os produtos beneficiados para o consumo também compõem essa Arca, como queijos, carnes curadas, pães e outros ativos que são considerados expressões enraizadas na cultura local. Para ser inserido nesse catálogo o produto deve ser considerado tradicional de um território, conforme especifica o Slow Food (2018, p. 68):

[...] os produtos ${ }^{5}$ devem ter vínculo forte com o território, não somente em termos de clima e ambiente, mas também do ponto de vista histórico e cultural. [...] O território é o solo, ar, água e clima, mas também é idioma, dialeto, religião, artesanato arquitetura e paisagem. Longe de seu território de origem, uma semente, uma planta, uma árvore ou uma raça animal são reduzidos ao seu material genético.

\footnotetext{
${ }^{5}$ No sentido abordado pelo texto, "o produto pode ser uma espécie doméstica (uma variedade de planta comestível ou ecótipo, raça ou população animal), uma espécie selvagem (quando ligada a técnicas de colheita e processamento específicas, e usos tradicionais) ou um produto processado (que deve ter uma qualidade organoléptica específica, definida pelo uso e pelas tradições locais; deve ter ligação com os saberes locais tradicionais e com o território, memória e identidade de uma comunidade; deve ser produzido em quantidades limitadas, usando métodos artesanais; e deve estar em risco de extinção)", (SLOW FOOD, 2013b, p. 6).
} 
Para além dos benefícios de classificar, descrever e catalogar esses alimentos (ativos), a Arca do Gosto atrai a atenção e interesse do consumidor para produtos com potencial comercial e produtivo (FERREIRA, 2009), incentivando a sua procura para consumo e, consequentemente na sua disponibilidade em mercados específicos.

A atuação do Slow no intuito de introduzir alimentos da Arca do Gosto em pontos de comercialização significa, para muitos produtores rurais, a oportunidade de dispor os seus produtos em um mercado que em alguns contextos se mostram excludentes. Essa realidade justifica-se pelo fato de alguns países, como a exemplo do Brasil, não legalizarem a venda de produtos produzidos fora das especificações técnicas dos seus órgãos regulamentadores.

\begin{abstract}
Em 2001, o Slow Food lançou uma campanha [Slow Cheese] para proteger os queijos feitos com leite cru e conseguiu mais de 20 mil assinaturas para defender os direitos dos queijeiros nos países onde leis sanitárias higienistas proíbem ou prejudicam a produção desse tipo de queijo. [...] O Slow Food se posiciona em favor dos produtores de queijo, sobretudo em países como Brasil, Estados Unidos, Irlanda, Grã Bretanha e Austrália, onde as regulamentações são muito rígidas [...]. No Brasil, apesar de existirem centenas de queijos de leite cru por todo o território nacional, eles são geralmente marginalizados e muito poucos são conhecidos pela população (SLOW FOOD, 2018, p. 15).
\end{abstract}

Os mercados revelam, nesses casos, algumas das dificuldades enfrentadas pelos produtores artesanais em inserirem seus produtos em um fluxo de comercialização legalizado. Essas barreiras afetam diretamente na economia dos territórios, enfraquecendo a organização da produção local. "Daí o vínculo tão íntimo entre territórios e mercados: é que as regras em torno das quais funcionam os mercados de uma determinada região refletem a correlação entre os diferentes grupos sociais que deles participam e dependem" (ABRAMOVAY, 2010, p. 43).

Nesse âmbito, não é tarefa difícil visualizar os próprios movimentos sociais como protagonistas de certas mudanças que ocorrem na estrutura dos mercados, pois, interferem diretamente na forma de distribuição e consumo, bem como nos modelos de negociações que, de certa forma, regulam a oferta e procura dos produtos (ABRAMOVAY, 2010). Esses movimentos também são capazes de fazer intervenções com potencial de construir mercados novos. Desta forma, os Mercados da Terra são uma ação do Slow Food que 
ilustra bem essa perspectiva, levando em consideração que são "feiras de agricultores, estabelecidas de acordo com as diretrizes que seguem a filosofia do movimento. Essas feiras [...] são importantes pontos de encontro social, onde produtores locais vendem alimentos de qualidade diretamente ao consumidor" (SLOW FOOD, 2018, p. 112).

Analisados sob uma ótica estratégica, os consumidores na condição de atores ligados ao território e estimulados pelo Slow Food à cooperarem com o movimento, não acessam esses produtos apenas nos eventos dos Mercados da Terra. Com o estreitamento da produção e consumo, as vantagens não se voltam somente para os agricultores, visto que consumidores considerados como auto-organizados podem gerenciar diretamente a venda dos alimentos. Essa dinâmica é mantida pelos chamados Grupos de Consumo Responsável (GCR), compostos por indivíduos dispostos a adquirirem alimentos de forma coletiva (SLOW FOOD, 2018).

Em termos de regras, alguns participantes podem realizar o pagamento antecipado, que de acordo com o Slow Food (2018, p. 112) "promove a segurança de uma venda garantida e colabora, também, em fases de planejamento do plantio para obter uma determinada variedade ou quantidade de alimentos" no território. Essa relação de produção (agricultor) e co-produção (consumidor) é uma das bases fundamentais para a construção social dos territórios rurais, incluindo nessa tessitura a interação do "ruralurbano". Convergindo com essa realidade, Pecqueur (2005, p. 16) afirma que o processo de construção territorial "pelos atores não convoca apenas os produtores, mas também os consumidores. Pois, nesse quadro, não se pode separar as condições da produção dos bens e serviços do território por seus atores, da saída mercantil desses produtos".

Preocupado com a segurança do alimento e a sua comunicação transparente para o consumidor, o Slow auxilia os agricultores a desenvolverem etiquetas narrativas que disponham de informações sobre a origem dos produtos que estão sendo ofertados. É uma estratégia que agrega mais valor ao produto, ou conforme a literatura própria do desenvolvimento territorial, valoriza o ativo territorial. Para tanto, é preciso selecionar bem o conteúdo que deverá ser posto nesses dispositivos.

Segundo o Slow Food (2015), a qualidade de um produto alimentar deve ser pensada e analisada a partir de uma narrativa que, via de regra, tem como ponto de 
partida o seu lugar de origem - o território. Esse discurso faz menção à inclusão das técnicas de produção praticadas pelos agricultores, vinculando as heranças culturais passadas de uma geração para outra, a forma de processamento artesanal desses alimentos, seus métodos de conservação, seus atributos naturais (singularidades organolépticas e nutricionais) e as características ambientais que compõem a sua paisagem.

Na Figura 1 é possível observar a natureza das informações de uma etiqueta narrativa do mel de abelha Mandaçaia da Caatinga, cultivado na região Nordeste do Brasil. Os aspectos da paisagem que constitui o território são fortemente destacados, revelando ao mercado consumidor a biodiversidade do local e a sua singularidade em relação à outras regiões.

\section{Figura 1 - Modelo de Etiqueta Narrativa do Mel de Abelha Mandaçaia da Caatinga}

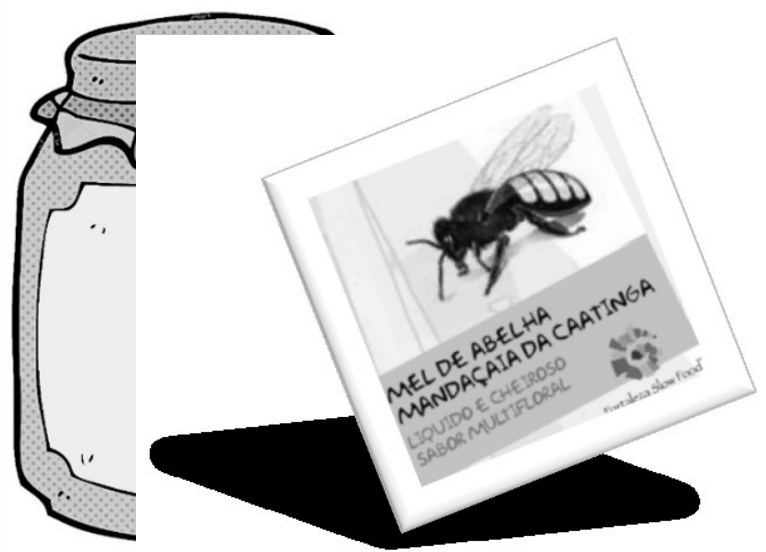

\section{O território}

Os meliponicultores pertencem as comunidades dos territórios do Piemonte da Diamantina e da Bacia do Jacuípe, Bahia - Nordeste do Brasil. Esta região semiárida se caracteriza pelo bioma da Caatinga, do tupi, "mata branca": fase da seca que cai todas as folhas das árvores, assumindo uma cor verde apenas durante a estação chuvosa. A florada é típica do bioma Caatinga, imprimindo suas características na cor, aroma e sabor multifloral.

\section{As abelhas}

Pertencem à espécie melípona quadrifasciata anthidioides: uma abelha nativa sem ferrão, com cabeça e tórax pretos e abdome com faixas amarelas interrompidas e asas de cor ferrugem. São criadas em colmeias verticais (seguindo o padrão natural dos favos de cria nos troncos das árvores) produzidas pelos jovens da Fortaleza. No período de maior seca. São alimentadas com mel. Cada colmeia pode produzir até 1,5 litros de mel no ano.

\section{O período e a técnica de produção}

O mel se produz geralmente após o período de chuva, variavelmente, entre os meses de novembro e abril. É extraído manualmente de forma a conservar os favos. Manter o produto sob refrigeração para evitar a fermentação.

Fonte: Adaptado de Slow Food (2016). 
De acordo com Cazella, Bonnal e Maluf (2009), a paisagem de um território é um bem público que pode ser preservado pela agricultura familiar (levando em consideração o seu caráter multifuncional ${ }^{6}$ ), porém a sua discussão e inserção nas agendas políticas de desenvolvimento territorial brasileiras é incipiente. Por conseguinte, a preservação das paisagens rurais deve ser entendida como um esforço urgente e contínuo das implementações estratégicas do Estado em conjunto com os demais atores territoriais, frente às ameaças que surgem das atividades industriais. Para o Slow Food (2013b, p.8),

paisagens também correm o risco de desaparecer, sendo abandonadas, reduzidas ou pavimentadas devido à urbanização, industrialização, agricultura industrial ou despovoamento. Além disso, em alguns países em desenvolvimento, ecossistemas rurais podem estar sujeitos à grilagem, uma nova forma de colonialismo, onde a terra é tomada das populações locais/rurais. Ou pode ser destruída pelo desmatamento ou superexploração, devido à falta de conhecimento das consequências ambientais de algumas práticas (como a técnica das queimadas).

Como forma de contribuir para a preservação das paisagens, do tecido cultural enraizado nas histórias, no modo de produção e tessitura das relações presentes no território, o Slow Food lançou em 1999 um projeto denominado "Fortalezas". Geralmente, a execução desse projeto é uma etapa que sucede o registro de um produto na Arca do Gosto, tendo como objetivos principais preservar: "1. Um produto tradicional em risco de extinção (um produto da Arca do Gosto); 2. Uma técnica de produção tradicional em risco de extinção (p. ex., pesca, criação, processamento ou cultivo); 3. Uma paisagem rural ou ecossistema em risco de extinção" (SLOW FOOD, 2013b, p.5).

A criação das Fortalezes em torno de um determinado produto presume que os produtores adotem os critérios de sustentabilidade ambiental (limpo) e socioeconômica (justo). Com base nessas orientações, as técnicas de produção utilizadas pelos agricultores devem "preservar a fertilidade da terra e dos ecossistemas hidrográficos, evitar o uso de produtos químicos e manter métodos tradicionais de cultivo e de gestão da terra sempre que possível" (SLOW FOOD, 2013b, p.10). No intuito de beneficiar uma

\footnotetext{
${ }^{6}$ A abordagem da multifuncionalidade "rompe com o enfoque setorial e amplia o campo das funções sociais atribuídas à agricultura que deixa de ser entendida apenas como produtora de bens agrícolas. Ela se torna responsável pela conservação dos recursos naturais (água, solos, biodiversidade e outros), do patrimônio natural (paisagens) e pela qualidade dos alimentos" (Carneiro; Maluf, 2003, p. 19).
} 
coletividade, em especial os produtores envolvidos no cultivo e os seus consumidores, as Fortalezas devem sempre envolver uma Comunidade do Alimento (grupo de indivíduos ligados a um alimento e território específicos). Assim, os agricultores são favorecidos e têm autonomia para tomar decisões relacionadas aos projetos destinados à otimização das suas atividades produtivas, como a exemplo da elaboração do protocolo de produção a ser seguido por eles e a introdução de métodos inovadores.

Isso posto, se ressalta que essa forma de valorizar os recursos e ativos territoriais, a partir das estratégias Slow Food, não isenta ou exclui o papel e participação do Estado nesse processo. Ao contrário dessa ideia de distanciamento, o movimento busca nessa entidade a parceria para o financiamento dos seus projetos, como o executado no Brasil com início em 2016, de título "Alimentos Bons, Limpos e Justos: ampliação e qualificação da participação da agricultura familiar brasileira no Movimento Slow Food".

A realização de projetos dessa natureza, que incluem e qualificam os agricultores familiares, contribui para uma reestruturação da organização produtiva presente no território. Os conhecimentos difundidos pelo Slow Food, com a oferta de cursos fundamentados em temas de interesse dos produtores rurais, reforçam e acrescentam no saber-fazer local boas formas de se relacionar com os alimentos orgânicos vinculadas aos aspectos socioambientais, socioculturais e socioeconômicos próprios da localidade a que se destina a capacitação.

Até meados do primeiro semestre de 2018, esse projeto realizado no Brasil em parceria com a UFSC e a SEAD do Governo Federal contava com mais de 600 indivíduos inscritos para participarem desse tipo de qualificação. A expectativa é que esses participantes sejam multiplicadores do conteúdo abordado durante a realização do curso, analítico do funcionalismo-estruturalista, pois a sua abordagem considera que os elementos de características simbólicas expressos nas tradições e costumes de uma localidade específica interferem diretamente no seu processo de desenvolvimento econômico e social. Destarte, a identificação das ações estratégicas voltadas para desenvolver os territórios rurais deve partir da análise das relações entre os seus diversos participantes. 
Nesse contexto, o Slow Food, enquanto movimento da sociedade civil vem desempenhando um importante papel na implementação de estratégias que, muitas vezes, definem como certas localidades rurais poderão preservar o seu tecido cultural. A sua atuação, em nível internacional, com base na filosofia "alimentos bons, limpos e justos" atinge dimensões territoriais consideradas complexas por apresentarem conflitos de interesse que envolve diferentes atores.

Na dimensão socioeconômica foi identificado que o desempenho do Slow Food em criar redes de cooperação, com destaque para o estreitamento das relações entre produtores e consumidores, contribui de maneira significativa para dispor os produtos orgânicos e artesanais nos mercados. Essa ação, implica na aproximação do rural com o urbano, incentivando a sociedade a valorizar as ruralidades, além de chamar a atenção dos órgãos reguladores do Estado para a viabilidade da comercialização de alguns produtos proibidos por lei em determinados países.

A busca por esse reconhecimento resulta na introdução de técnicas inovadoras e seguras no cultivo e processamento desses alimentos, incluindo os seus produtores como agentes ativos e autônomos na elaboração de protocolos de produção e beneficiamento. Por sua vez, essas implementações nos sistemas produtivos localizados requerem à observância e execução de práticas sustentáveis, com vistas a preservar a biodiversidade e o saber-fazer enraizado na cultura do território, tratando-se, por tanto, de estratégias ligadas respectivamente às dimensões socioambientais e socioculturais.

Por fim, o movimento ressalta a parceria do Estado na elaboração e execução de projetos de autoria do Slow Food. Diante do exposto neste artigo, sugere-se uma nova reflexão em relação ao que pode ser compreendido como fronteiras de atuação desses dois atores, no que tange ao processo de desenvolvimento territorial das regiões rurais, posto que, no âmbito do funcionamento dos mercados, podem atuar em cooperação ou em oposição em virtude dos seus interesses. 


\section{Referências}

ABRAMOVAY, R. Para uma Teoria dos Estudos Territoriais. In: VIEIRA et al., Desenvolvimento Territorial Sustentável no Brasil: subsídios para uma política de fomento. Florianópolis: APED: Secco, 2010.

BONNAL, P.; CAZELLA, A. A.; Delgado, N. G.. Contribuições ao Estudo do Desenvolvimento Territorial Rural: reflexões metodológicas a partir do caso brasileiro. Biblio 3W. Revista Bibliográfica de Geografía y Ciencias Sociales. [En línea]. Barcelona: Universidad de Barcelona, 30 de noviembre de 2012, v. XVII, n. 1002.

BOURDIEU, P. Outline of a Theory Practice. Cambridge: Cambridge University, 1977.

CARNEIRO, M. J.; Maluf, R. S. Introdução. In: CARNEIRO, M. J.; MALUF, R. S (orgs.). Para Além da Produção: multifuncionalidade e agricultura familiar. Rio de Janeiro: Mauad, 2003. p. 17-27.

CARRIÈRE, J-P; CAZELLA, A. A. Abordagem introdutória ao conceito de desenvolvimento território. Eisforia, Florianópolis, v. 4, n. especial, p. 23-48, dez.2006.

CAZELLA, A.; BONNAL, P.; Maluf, R. Olhares disciplinares sobre território e desenvolvimento territorial. In: Cazella, A.; Bonnal, P.; Maluf, R. Agricultura Familiar: multifuncionalidade e desenvolvimento territorial no Brasil. Rio de Janeiro: Mauad X, 2009.

COSTA, C. F. DA. A Boa Comida no Início do Século XXI - Entre Carlo Petrini e Michael Pollan. 2015. 85 fls. Dissertação (Mestrado em Alimentação - Fontes, Cultura e Sociedade) - Universidade de Coimbra, Coimbra, 2015.

DAL SOGLIO, F. K. A Agricultura Moderna e o Mito da Produtividade. 2016. In: Dal Soglio, F. K.; Kubo, R. R. (Orgs). Desenvolvimento, Agricultura e Sustentabilidade. Coordenado pela SEAD/UFRGS. - Porto Alegre: Editora da UFRGS, 2016.

DALLABRIDA, V. R. Ativos Territoriais, Estratégias de Desenvolvimento e Governança Territorial: uma análise comparada de experiências brasileiras e portuguesas. EURE (Santiago. En línea), v. 42, p. 187-212, 2016.

DENARDIN, V. F. Desenvolvimento Territorial e Estratégias de Valorização da Origem de Bens Alimentares. 2016. In: Wilkinson, J.; Niederle, P. A.; Mascarenhas, G. C. C. (Orgs). O Sabor da Origem: produtos territorializados na nova dinâmica dos mercados alimentares. Porto Alegre: Escritos do Brasil, 2016.

FERREIRA, A. R. A. C.. O Movimento Slow Food. Porto, 2009. Monografia (Faculdade de Ciência da Nutrição e Alimentação), Universidade do Porto. 
GRANOVETTER, M. Economic Action and Social Structure: the problem of embeddedness. American Journal of Sociology, V. 91, n. 3, p. 481-510, 1985.

GRAZIANO DA SILVA, J. A modernização dolorosa: estrutura agrária, fronteira agrícola e trabalhadores rurais no Brasil. Rio de Janeiro: Zahar, 1981.

HAESBAERT, R. LIMONAD, E. O Território em Tempos de Globalização. Etc: espaço, tempo e crítica, Niterói, UFF, v.1, n. 2, p. 39-52, ago de 2007.

HARVEY, D. Condição Pós-Moderna. 18. ed. São Paulo: Edições Loyola, 2009.

OLIVEIRA, D. C. Comida, Carisma e Prazer: um estudo sobre a constituição do Slow Food no Brasil. 2014. 210 fls. Tese (Doutorado em Ciências Sociais em Desenvolvimento, Agricultura e Sociedade) - Universidade Federal Rural do Rio de Janeiro, Rio de Janeiro, 2014.

PECQUEUR, B. O Desenvolvimento Territorial: uma nova abordagem dos processos de desenvolvimento para as economias do sul. Raízes, Campina Grande, v. 24, n. 1 e 2, p. 1022, jan./dez. 2005.

PETRINI, C. SLOW FOOD: princípios da nova gastronomia. Trad. de Renata Lúcia Botina. São Paulo: Editora Senac, 2009. 245 p.

RAFFESTIN, C. Por uma Geografia do Poder. Tradução de Maria Cecília França. São Paulo: Ática, 1993.

SANTOS, M. A natureza do espaço. São Paulo: Hucitec, 1996.

SLOW FOOD. As Fortalezes Slow Food: como criar uma Fortaleza, estabelecer relações com os produtores, organizar as atividades do projeto. Slow Food, 2013b.

Biodiversidade, Arca do Gosto e Fortalezas Slow Food: um guia para entender o que são, como se relacionam com o que comemos e como podemos apoiá-las. Glennn Makuta, São Paulo, 2018.

. Bem-Vindos ao Nosso Mundo: o manual. Slow Food, $2013 a$.

. Boas Práticas para o Bem-estar das Abelhas Nativas sem Ferrão: a Fortaleza Slow Food do mel de abelha Mandaçaia da caatinga em foco. Slow Food, 2016.

. O Rótulo Narrativo: uma revolução na comunicação do alimento, pequeno guia para a realização do rótulo. Slow Food, 2015. 